\title{
Research on the Top-design of Intelligent Environmental Protection
}

\author{
CHEN Yuanhua ${ }^{1,}$, , LIU Yu ${ }^{1}$, LI Jie ${ }^{1}$, ZHANG Lina ${ }^{1}$ \\ ${ }^{1}$ CECEP Liuhe and Talroad Environmental Technology Co., Ltd, Beijing, 100082, China. \\ ayuanhua.chen@talroad.com.cn
}

Keywords: Intelligent environmental protection, comprehensive control system

Abstract. Intelligent environmental Protection is a complicated systematic project, involving all aspects of environmental management, which is based on the overall situation and also given attention to the details. Hence, it is necessary to make overall planning on the top-level design of smart environmental protection, with organizational guarantee, policy and regulation guarantee, system guarantee, and integration of all aspects of resources, to establish a comprehensive control system of regional ecological environmental protection based on the population, legal persons and geospatial information, focused on the management system, supported by environment sensing data, regard cloud computing as analyze platform and applied for ecological environment management.

\section{Introduction}

Since IBM put forward the concept of "smart planet" in November 2008, the whole world has surged the construction of wisdom city, as the domestic competition to occupy the smart city commanding heights is in full swing [1]. Meanwhile the corresponding researches on wisdom energy, transportation, medical treatment, logistics and other industries also have been started, trying to make intellectual technology applied in various fields [2].

Along with the China's advancement of development process, the rapid growth of national economic and population, the huge consumption of resources and energy and the disturbance of human activities put great increasing pressure to ecological environment, and what's worse, industry transfer and resource development may produce new ecological damage in part sensitive ecosystem areas, making the task of ecological environment protection more difficult. Consequently, it requires all levels government departments to improve environmental monitoring and regulation in their respective administrative areas using advanced information technology, environmental monitoring technology and environmental monitoring equipments, for accurate detection of pollution indexes, real-time monitoring and early warning of certain and potential pollution sources. All this shows that wisdom environment is upon us [3].

Through application of information and communication technology, intelligent environmental protection can make intelligent response to various needs by perception, analysis, and integration of various kinds of environmental information, so as to make more suitable decisions to meet the needs of ecological environment development. This is a new concept and model of environmental protection, which can enhance the level of environmental informatization, promote pollutant discharge reduction, explore low-carbon and ecological green transitional development, realize sustainable development and scientific development, achieving the harmonious development among environment, mankind, economy and even society. The establishment of smart environmental protection will further improve the supervisory ability of eco-environment carrying capacity, perfect the environmental quality and pollution emitted unit online monitoring network, enhance the pollution causes and development trend analysis capacity, trace back pollution causes, intelligently analyze environment situation and industry trend, provide decision-making reference for government in city industry and eco-environment development, strictly according to the ecological red line protection system, in order to boost healthy development of our country's ecological environment. 


\section{Intelligent Environmental Protection Positioning}

First, smart city, making full use of information and communication technology to perceive, analyze and integrate the key information of city core operation system, is the urban life morphology to intelligently respond to all sorts of requirements, including the people's livelihood, environmental protection, public security, urban services, commercial and industrial activities, as shown in figure 1.

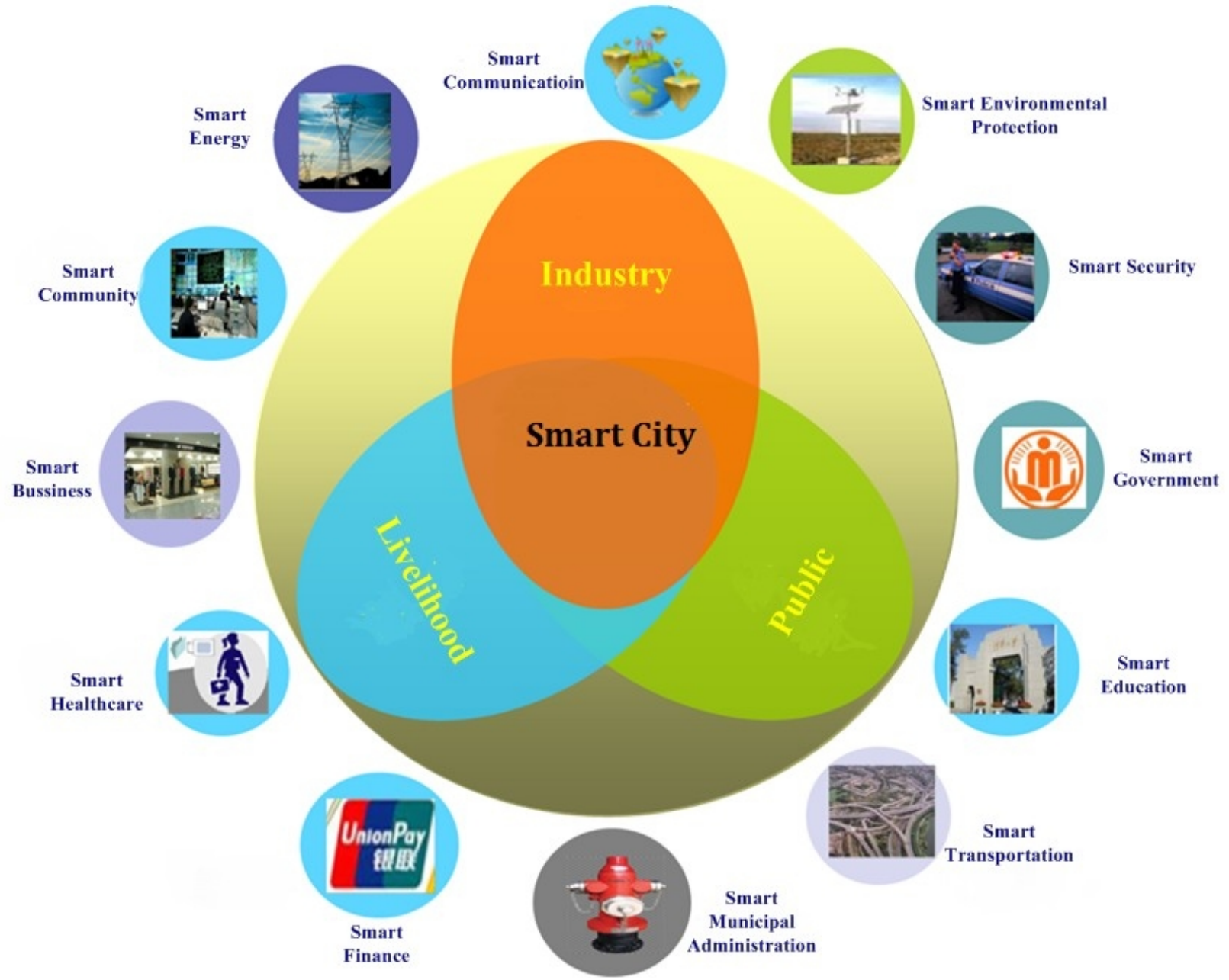

Fig. 1 The contents of smart city construction

Thus it can be seen that, smart environmental protection as part of wisdom urban, has been more closely related and keeping trends similar to construction of intelligent cities, in addition that it will also promote the smarter city construction development. In essence, smart environmental protection is the extension and expansion of digital environment, using the Internet of things technology by sensors and equipment embedded in various environmental monitoring objects. Through combining supercomputers with cloud computing, the human society combined with environmental business systems, will implement environmental management and decision making in a more elaborate and dynamic way.

\section{The Framework of Top-design}

Under the guidance of the national strategy that information improves environmental protection strength, information has become a key means to reform and innovation in environmental management mode, and to raise the environmental fine management level. In consideration of the complexity and comprehensiveness of energy conservation and environmental protection business, the top design of environmental information industry has been proved particularly essential and urgent, possessing important strategic significance. This paper strives to promote effect of smart environmental protection construction and application by means of overall planning and top-level design. As the deep 
understanding of requirements on environmental protection business and deepened application of environmental information, the top design system of smart environmental protection, focusing on interconnection and resource sharing, has been established, as shown in figure 2.

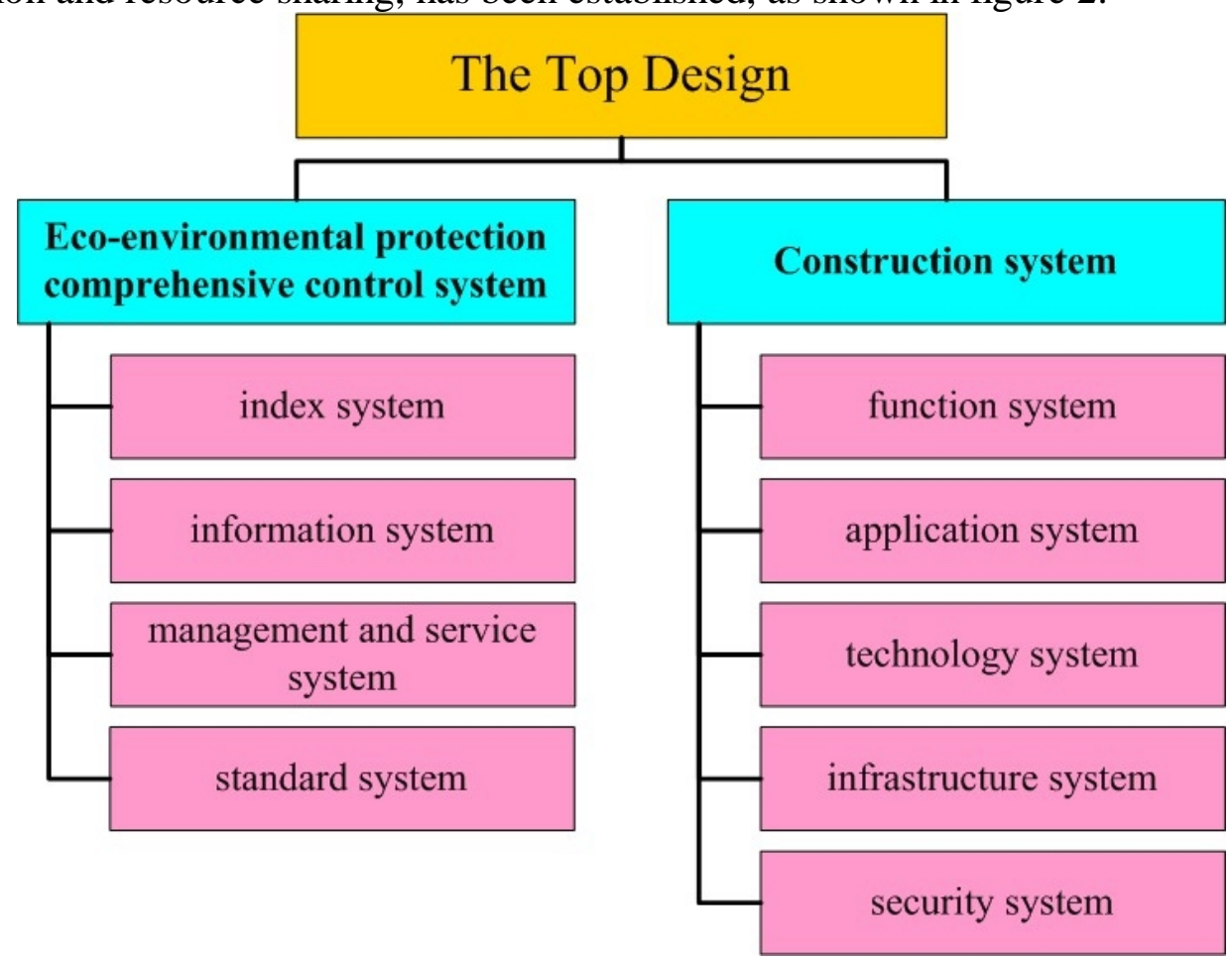

Fig.2 The Top-design Framework of intelligent environmental Protection

The top-design framework mainly includes comprehensive control system and construction system. The comprehensive control system containing index system, information system, management and service system, and standard system, is the construction planning for top-level design, which determines the development direction of intelligent environmental protection, and is the emphasis of the framework for its scientificity, rationality and applicability can determines the construction success or failure. Relatively, construction system including function system, application system, technology system, infrastructure system and security system, is execution planning for smart environmental protection.

\section{The contents of Top-design}

Eco-environmental protection comprehensive control system. As the development direction of intelligent environmental protection, ecological environment protection comprehensive control system is mainly composed of planning and mechanism system. Through the comb of comprehensive environmental protection management requirements, regional efficient control index, method and standard, including pollution sources monitoring, environmental emergency management, pollution charge, pollution complaints, construction project examination and approval, nuclear and radiation management, resource sharing and business collaboration, and ecological environmental management, should be set up.

The preparation of eco-environmental protection planning is by space resource allocation, and redistribution of human and nature value, such as economic value, social value and environmental value, forming clarity of thought on construction. The role of mechanism system is to determine fundamental principle that must be followed, to regularize behavior by policy, and to promote the planning content implemented smoothly.

Construction system. Intelligent environmental protection construction system, based on cloud computing platforms, provides all kinds of applications and services for environmental protection industry users, for instance, environmental protection comprehensive business management service, 
environment online monitoring service, environmental emergency command and effective interaction service, supervision and law enforcement service, data sharing service, and environmental information database management services.

The construction system is adopted four layers architecture, namely environmental perceptual layer, information transmission layer, support layer and application layer. After collected by equipment in environmental perceptual layer, data is uploaded to the monitoring center through information transport network. The support layer is environmental cloud computing platform, creating software and hardware environments for central monitoring system application. The application layer is charge of managing application systems for specific business. System architecture is as shown in figure 3.

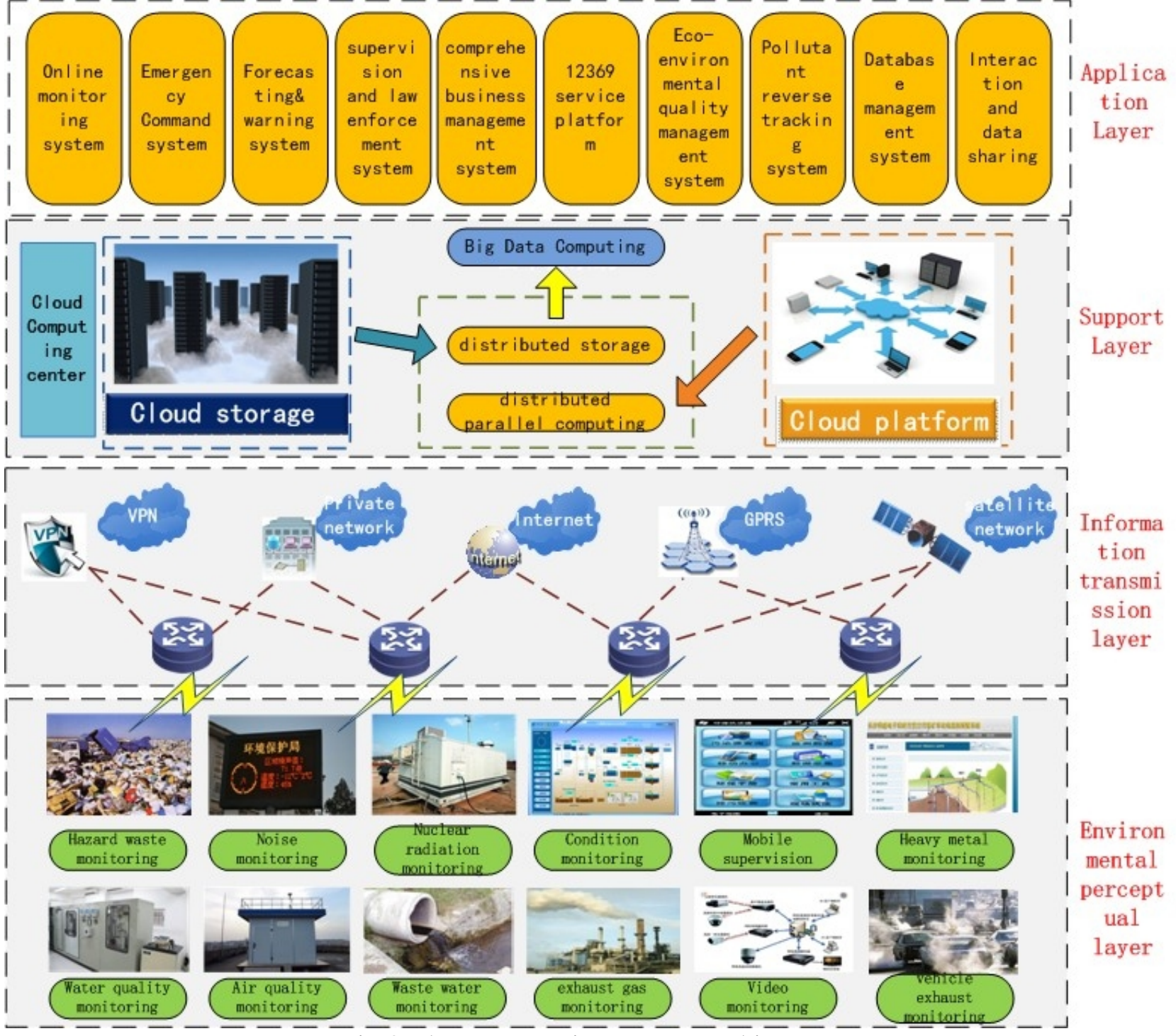

Fig. 3 The construction system architecture

Environmental perceptual layer

At the bottom of the system architecture, the perceptual layer is the foundation of all concrete applications, because of its Space-Air-Ground sensory ability, like environmental quality monitoring equipments, pollution source monitoring equipments, mobile law-enforcing equipments, multi-source satellite remote sensing equipments, nuclear radiation monitoring equipments, video monitoring equipments, motor vehicle exhaust emission monitoring equipments, hazardous wastes tracking RFID barcode, noise monitoring instruments, and drones. Particularly, the multi-source satellite remote sensing device can observe environmental changes through remote sensing image, the drone can obtain aerial photo data of pollution sources using loaded camera to supervise and analyze pollution sources, and other ground monitoring equipments and sensors can collect various environmental and pollutants parameters. 
Information transmission layer

The information transmission layer is mainly used for data collection, interaction and distribution, applying GPRS/CDMA network, 3G network, virtual private network, satellite communication network, VSAT network, environmental private network, and Internet network.

Support layer

The support layer provides basic services, like information collection, data distributed storage, distributed parallel computing, distributed process scheduling and management, for environmental protection cloud computing platform. The software and hardware environment is composed of servers, storage devices, virtualization software, middleware, application development platform, cloud operating system, database, load balancing and GIS platform.

Application layer

All application systems are deployed on environmental cloud platform, after a long-term and continuous data accumulation, real-time data analysis will be carried out to analyze and assess region's pollution status, pollution trend, industrial development situation, and to evaluate effectiveness of pollution control measures, for formation of environmental quality report, clarifying environmental quality variation tendency and pollution emission behavior, and putting forward effective policies and measures to improve environmental quality.

\section{Conclusion}

The construction of intelligent environmental protection will greatly improve the environmental protection management ability, promote the environmental protection work standardization, standardization and automation, promote data resource sharing and system integration, avoid repeated construction and information island, implement environmental information resources efficient utilization, improve environmental supervision and emergency precaution capacity, improve decision-making and service ability, provide support to make decision for management department to balance ecological environment, industrial and economic development, expand citizens' right to know about environment, and enhance the residents' environmental awareness.

\section{References}

[1] Wu Yong, Zhang Hongjian. Smart Environmental Protection Solution Based On Big Data and Cloud Computing[J]. Information Technology \& Standardization, 2013(11):38-41.

[2] Divyakant Agrawal, Stuipto Das, Amr El Abbadi. Big data and cloud computing: current state and future opportunities[C].Proceedings of the 14th International Conference on Extending Database Technology, 2011(3):530-533.

[3] Xu Min, Sun Hailin. From 'Digital Environmental Protection' to 'Smart Environmental Protection'[J]. The administration and technique of environmental monitoring, 2011,23(04):5-7. 